\title{
An Efficient Protocol for Micro Propagation of Ginger (Zingiber Officinale Rosc.) cv. Volvo via Sprout Bud Culture
}

\author{
Berihu Mengs \\ Plant Biotechnology research Laboratory, Ethiopian Institute of Agricultural Research (EIAR), P.O.Box: 2003. \\ Jimma Agricultural Research Center (JARC), P.O.Box: 192. Jimma, Ethiopia
}

\begin{abstract}
An efficient, simple micro propagation method was developed for Zingiber officinale Rosc.) cv. Volvo using fresh sprouting bud in basal culture media. Explants were cultured on to Murashige and Skoog's (MS) medium supplemented with different concentrations and combinations of BA (Benzyl adenine) and KIN (Kinetin) for shoot micro propagation and IBA (Indol-3-Butyric acid) and NAA ( $\alpha$ - Naphthalene acetic acid) for root induction. Explants cultured on MS basal medium supplemented with $2.0 \mathrm{mg} / \mathrm{L} \mathrm{BA}+0.5 \mathrm{gm} / \mathrm{L} \mathrm{KIN}$ gave the highest averages in shoot number (11.3 shoots/explant), leaf number (22.8 leaves/shoot) and highest plant height $(16.4 \mathrm{~cm})$ and followed by the concentration $2 \mathrm{mg} / \mathrm{L}$ of BA and $1 \mathrm{mg} / \mathrm{L} \mathrm{KIN}$ gave the highest averages of shoot number $(9.8$ shoots/explant), leaf number $(13.9$ leaves/shoot) and highest plant height $(10.3 \mathrm{~cm})$. In vitro shootlets were rooted on to the half strength MS basal media supplemented with the $1.0 \mathrm{mg} / \mathrm{L}$ NAA and followed by $1 \mathrm{mg} / \mathrm{L}$ IBA and $2 \mathrm{mg} / \mathrm{L}$ NAA obtained the highest averages of roots number and roots length were achieved $(9.6$ roots $/$ shoot and $11.1 \mathrm{~cm}$ respectively) and $(8.3$ roots $/$ shoot and highest length of roots $10.8 \mathrm{~cm}$ respectively. Rooted shoots were transplanted in the green house for hardening off planted at the mixture of forest soil, coffee husk and sand soil (2:1:1) ratio respectively and their survival was $96 \%$ in the field condition. Hence, the acclimatization seedlings were set edible rhizomes in cement bug and pot in seven months.
\end{abstract}

Keywords: Zingiber officinale, micropropagation, sprouting bud, Volvo, plant growth regulators and hardening off

DOI: $10.7176 / \mathrm{JNSR} / 12-17-02$

Publication date:September $30^{\text {th }} 2021$

\section{Introduction}

Ginger (Zingiber officinale Rosc.) in the family Zingiberaceae is an important tropical herbaceous horticultural perennial plant that grown as annual. Several authors have quoted different figures for the total number of genera and species but it is probably appropriate to quote the world record at least 51 genera and 1500 species (Newman, 2001). It is indigenous to tropical India, South East Asia, Australia and Japan with the main center of diversity in Indo-Malaysia (Purseglove, 1972).The Zinggiberaceae is an herbaceous spices moderate sized family of relatively advanced monocotyledonous plant of the order Zingiberales. Zingiberaceous plants are rhizomatous, perennial and aromatic herbs often of large size, bearing flowers either terminally on aerial leaf shoots or from ground level. Ginger rhizomes degenerate after long-term propagation, and it is difficult to breed new cultivars through normal crossing because of poor flowering and seed set (Zhao 2002) and Problems faced in ginger breeding have so far been the very low genetic variation in ginger plant. This is because ginger is vegetatively propagated crop and hybridization is not effective since its floral biology has not been properly observed yet (Simmonds, 1986). Despite the diseases are mainly transmitted by rhizomes propagated every year production of disease-free clones is necessary in order to get a successful ginger cultivation. The germplasm collections in clonal repositories are also seriously affected by bacterial wilt and fungal diseases. In addition, the incidence of ginger bacterial wilt disease because of Ralstonia solanaceurum in 2011/12 has been devastating to ginger in the country and almost all ginger producing areas had been affected by the disease and production reduced by more than 90 percent (Tariku et al., 2016). According to the survey results conducted in 2012, the wilt incidence in some of the survey areas such as Sheka zone was 93.5\% (Habetewold et al., 2015). Moreover since pathogenic nematode, fungi, bacteria or viruses are readily transmitted through traditional practices, it was judged important to develop a micro propagation technique and to make available for commercial use to the pathogen free ginger germplasm. In vitro regeneration of auxiliary bud and adventitious shoots from shoot tips has already been attempted by callus culture (Hosoki and Sagawa, 1977) and clonal multiplication methods through meristem tip culture have also been reported by (Pillai and Kumar, 1982; Smith and Hamill, 1996; Biruk et al., 2012). However in these methods, the micro propagation rate was not shown high enough to obtain disease free quality micro plantlets for commercial use, and the acclimatization of the plantlet was very slow and unsatisfactory. Slow multiplication rate limited availability of high yielding genotypes extensive field maintenance of planting material, high susceptibility to wilt and rot diseases that necessitates application of tissue culture techniques as a solution to these problems (Nayak and Naik, 2006). In vitro propagation has long been recognized as an efficient means for rapid clonal multiplication and conservation of important taxa. However in vitro culture is the best method as a continuous source of supply of disease free planting material for commercial utilization. The utility, 
the various method of propagation includes efficient cost, effective method of in vitro multiplication is essential for improvement of ginger. The most important role of in vitro propagation is to conserve the genetic variation and evolutionary process in viable populations of ecologically and commercially viable varieties/ genotypes in order to prevent their potential extinction. The high yielding varieties (Zingiber officinale Rosc. cv. Volvo) of ginger were collected from Areka Agricultural research center (AARC). The rhizomes were planted in the nursery bed for sprouting. The young fresh buds of sprouting rhizomes were used for in vitro propagation. In present study reports a rapid micropropagation of the elite cultivar (cv. Volvo) of Zingiber officinale using fresh sprouting bud as an explant which is not included in the earlier studies. Moreover this cultivar has high potential demand with good market value. The purposed of the study was to develop a technique for more rapid and more convenient clonal propagation of ginger in a cost effective manner for obtaining large scale diseases free planting material for off season and year round cultivation for the benefit of the farmers.

\section{Materials and Methods}

The elite cultivar of Volvo was collected from Areka Agricultural Research Centre (AARC). The seed rhizomes is heat treated by $50^{\circ} \mathrm{C}$ for $20 \mathrm{~min}$ in water bath and sowing in sterilized sand to maintain humidity in poly bags under green house with $70 \%$ shade. Sprout bud $1.5 \mathrm{~cm}$ length samples for establishment of explants were obtained after four weeks of planting.

\section{Surface Sterilization and inoculation of Explants}

The morphologically good and healthy sprout buds were washed under running tap water supplemented with detergents followed by surface sterilization in $0.3(\mathrm{w} / \mathrm{v})$ Ridom $80 \%$ supplemented with three drops of Tween 20 and rinsed with sterile water. The sprout bud have also pretreated using $3 \%(\mathrm{w} / \mathrm{v})$ copper sulphate $\left(\mathrm{CuSo}_{4}\right), \mathrm{PVP}$, ascorbic acid and citric acid as for 6 hours was the best for reducing contamination and browning (Berihu M., 2018 ) and then the explants were treated by $70 \%(\mathrm{v} / \mathrm{v})$ ethanol for $1 \mathrm{~min}$ in laminar air flow hood, flashed again in sterilized water. Then, they were disinfected using $30 \%(\mathrm{v} / \mathrm{v})$ sodium hypochlorite $(5 \%$ active chlorine ingredient) for $15 \mathrm{~min}$ under laminar air flow hood. Moreover, explants initiation cultured in hormone free media for two weeks and followed shoot multiplication in auxine and cytokinin as sole and/or combination fortified with full strength MS media for six weeks. Finally, disease free micro shoots were sub-cultured in $1 / 2$ MS media to root induced for five weeks. Therefore, Cultures were incubated in the dark room for the first four weeks of establishment at $25 \pm 2{ }^{\circ} \mathrm{C}$ followed by $16 / 8 \mathrm{~h}$ photoperiod conditions and the light intensity of $40 \mu \mathrm{mol} \mathrm{m} \mathrm{m}^{-2} \mathrm{~s}^{-1}$ provided by cool white fluorescent lamps. Main while, the completed in vitro plantlets were acclimatized in the green house on the unsterilized 2:1:1 soil mixture of forest soil, coffee husk and sand respectively for five months.

\section{Data analysis}

Data were analyzed using the analysis of variance (ANOVA) using completely randomized design (CRD) of SAS statistical software version 9.3. The mean variability's among treatments were compared using the least significant difference (LSD) test at property 0.05 (GenStat. 2012).

\section{Results and discussion Initiation stage}

The sprout bud was cultured in Murashige and Skoog (MS) medium fortified with 30g/Lsucrose, $7 \mathrm{~g} / \mathrm{L}$ agar and the $\mathrm{pH}$ of medium had been adjusted to 5.8 prior to autoclaving at $121^{\circ} \mathrm{C}$ for $15 \mathrm{~min}$. For cost effective initiation was inoculated at plant hormone free MS media and germinated shoot after six weeks (Berihu M., 2018). Therefore, Cultures were incubated in $25 \pm 2{ }^{\circ} \mathrm{C}$ followed by $16 / 8 \mathrm{~h}$ photoperiod conditions and the light intensity of $40 \mu \mathrm{mol} \mathrm{m} \mathrm{m}^{-2} \mathrm{~s}^{-1}$ provided by cool white fluorescent lamps.

\section{Multiplication stage}

Table (1) and figure (1) showed the effect of different concentrations of BA, KIN and their interactions on the average number of multiplied shoots, number of leaves and plant height. There was a significant increasing in shoot numbers, number of leaves and plant height with the hormonal concentration effect of $2 \mathrm{mg} / \mathrm{L} \mathrm{BA}$ sole to reach the highest averages of (5.8 shoot/explant, 9.0 number of leveas and $10.0 \mathrm{~cm}$ plant height). The needing of addition of cytokinines hormones for shoot multiplication medium was recorded by previous studies to ginger in vitro micropropagation (Biruk et al., 2012). Moreover, the hormonal interaction between BA and KIN, the medium supplemented with $2.0 \mathrm{mg} / \mathrm{L} \mathrm{BA}+0.5 \mathrm{mg} / \mathrm{L} \mathrm{KIN}$ gave the highest averages in shoot number $(11.3$ shoot/explant), leaf number (22.8 leaves/shoot) and highest plant height $(16.4 \mathrm{~cm})$ and followed by the concentration $2 \mathrm{mg} / \mathrm{L}$ of BA and $1 \mathrm{mg} / \mathrm{L} \mathrm{KIN} \mathrm{gave} \mathrm{the} \mathrm{highest} \mathrm{averages} \mathrm{of} \mathrm{shoot} \mathrm{number} \mathrm{(} 9.8$ shoot/explant), leaf number (13.9 leaves/shoot) and highest plant height $(10.3 \mathrm{~cm})$. These results were supported by Biruke et al., (2012) in micro propagation of yali and boziab cultivars. The interaction between BA and KIN is very important 
in vegetative mass multiplication cv. Volvo cultivars as compared to control and BA alone for average shoot and leaf number as well as plant height of the explants. The highest shoot number was obtained on medium supplemented with $2.0 \mathrm{mg} / \mathrm{L} \mathrm{BA}$ in combination with $0.5 \mathrm{mg} / \mathrm{L} \mathrm{KIN}$ in volvo variety. Similarly, if regeneration is directly from the explants without passing through callus phase, that can be used for mass propagation of trueto- type clones. Although in vitro regeneration experiments were done on ginger varieties of Boziab and Yali using axillay bud (Biruk et al., 2012).

Table 1: The effect of various concentration levels of BA and KIN on shoot and leaf number and plant height of in vitro micro propagation of ginger cv. Volvo after eight weeks

\begin{tabular}{|c|c|c|c|c|}
\hline \multicolumn{2}{|c|}{ Plant Growth Regulators $(\mathrm{mg} / \mathrm{L})$} & \multirow[b]{2}{*}{ Shoot number } & \multirow[b]{2}{*}{ Leaf number } & \multirow[b]{2}{*}{ Plant height $(\mathrm{cm})$} \\
\hline BA & KIN & & & \\
\hline 0 & 0 & $1.0^{\mathrm{j}}$ & $1.7^{\mathrm{m}}$ & $6.3^{\mathrm{h}}$ \\
\hline 1 & 0 & $2.9^{\mathrm{h}}$ & $5.0^{\mathrm{k}}$ & $8.9^{\mathrm{e}}$ \\
\hline 2 & 0 & $5.8^{\mathrm{d}}$ & $9.0^{\mathrm{h}}$ & $10.0^{\mathrm{d}}$ \\
\hline 3 & 0 & $4.8^{\mathrm{e}}$ & $10.8^{\mathrm{f}}$ & $14.4^{\mathrm{b}}$ \\
\hline 4 & 0 & $4.4^{\mathrm{ef}}$ & $8.0^{\mathrm{i}}$ & $8.1^{\mathrm{f}}$ \\
\hline 5 & 0 & $3.6^{\mathrm{g}}$ & $6.7^{\mathrm{j}}$ & $7.5^{\mathrm{fg}}$ \\
\hline 1 & 0.5 & $6.9^{c}$ & $12.8^{\mathrm{e}}$ & $11.7^{\mathrm{c}}$ \\
\hline 2 & 0.5 & $11.3^{\mathrm{a}}$ & $22.8^{\mathrm{a}}$ & $16.4^{\mathrm{a}}$ \\
\hline 3 & 0.5 & $9.6^{\mathrm{b}}$ & $19.3^{\mathrm{b}}$ & $11.9^{c}$ \\
\hline 4 & 0.5 & $4.1^{\mathrm{fg}}$ & $7.6^{\mathrm{i}}$ & $5.7^{\text {hi }}$ \\
\hline 5 & 0.5 & $2.0^{\mathrm{i}}$ & $4.0^{\mathrm{k}}$ & $4.5^{\mathrm{j}}$ \\
\hline 1 & 1 & $3.6^{\mathrm{g}}$ & $7.7^{\mathrm{i}}$ & $7.1^{\mathrm{g}}$ \\
\hline 2 & 1 & $9.8^{\mathrm{b}}$ & $13.9^{\mathrm{d}}$ & $10.3^{\mathrm{d}}$ \\
\hline 3 & 1 & $7.0^{\mathrm{c}}$ & $17.5^{\mathrm{c}}$ & $9.0^{\mathrm{e}}$ \\
\hline 4 & 1 & $4.8^{\mathrm{e}}$ & $9.8^{\mathrm{g}}$ & $5.3^{\mathrm{i}}$ \\
\hline 5 & 1 & $1.4^{\mathrm{ij}}$ & $2.1^{\mathrm{m}}$ & $3.8^{\mathrm{k}}$ \\
\hline \multicolumn{2}{|c|}{ Mean } & 5.21 & 9.94 & 8.83 \\
\hline \multicolumn{2}{|c|}{ F-test } & $* *$ & $* *$ & $* *$ \\
\hline \multicolumn{2}{|c|}{ LSD@5\% } & 0.73 & 0.64 & 0.69 \\
\hline \multicolumn{2}{|c|}{ CV \% } & 8.39 & 3.87 & 4.75 \\
\hline
\end{tabular}

** Significant@ $\mathrm{P}<0.01$, Means with same letter within a column are not significantly different at $p<0.05$ ANOVA at least significance difference (LSD), $\mathrm{CV}=$ percent of coefficient variation, BA= Benzyl adenine and $\mathrm{KIN}=$ Kinetin

\section{Rooting stage}

Results in table (2) and figure (1) showed the effect of IBA and NAA concentrations individually on rooting response, average number of roots and roots length of ginger micro shoots that were cultured on half strength MS medium after six weeks of culture. It can be noticed that there was no significant difference among $1 \mathrm{mg} / \mathrm{L}$ IBA and $2 \mathrm{mg} / \mathrm{L}$ NAA auxin concentrations in rooting response for this variety, but there were significant as compared with control treatment (MS free hormone medium which did respond to root spontaneously produced in the shoot multiplication MS media this in vitro shoots were planted directly to artificial soil media combination of forest soil, coffee husk and sand soil 2:1:1 ratio respectively), whereas the highest averages of roots number and roots length were obtained at $1.0 \mathrm{mg} / \mathrm{L}$ NAA $(9.6$ roots/shoot and $11.1 \mathrm{~cm}$ respectively). Results from same table, showed that the concentration $2.0 \mathrm{mg} / \mathrm{L}$ NAA gave the highest rooting response (95\%), highest average of roots number $(8.3$ roots/shoot) and highest length of roots $(10.8 \mathrm{~cm})$. These results were in agreement with those observed by (Biruk, et al.,2012), who found that the reduction of MS salts levels in medium to half strength increased rooting of many plant species. The decreasing in MS medium salts levels to half or quarter means the decreasing in nitrogen levels in medium and then in shoots which causing the increasing in carbohydrates accumulation and this may result in increasing the root primordial and root numbers (Gawel, N.J., et al., 1990). Furthermore, the results proved that the auxins have an important role in rooting process, since they promote adventitious roots initiation in the bases of in vitro cultured shoots, so the exogenous supplying of auxins at optimal concentration would increase this process (Hartmann, H.T., et al., 1997). 
Table 2: The effect of different levels of IBA and NAA at $1 / 2$ MS media on root number and length response of $i n$ vitro generated shootlets of ginger cv. Volvo after six weeks

\begin{tabular}{|c|c|c|c|}
\hline \multicolumn{2}{|c|}{ Plant Growth Regulators (mg/L) } & \multirow[b]{2}{*}{ Root number } & \multirow[b]{2}{*}{ Root length $(\mathrm{cm})$} \\
\hline IBA & NAA & & \\
\hline 0 & 0 & $6.5^{\mathrm{c}}$ & $9.3^{\mathrm{b}}$ \\
\hline 1 & 0 & $8.3^{\mathrm{b}}$ & $10.8^{\mathrm{a}}$ \\
\hline 2 & 0 & $5.3^{\mathrm{d}}$ & $8.5^{\mathrm{b}}$ \\
\hline 3 & 0 & $4.0^{\mathrm{e}}$ & $6.1^{\mathrm{c}}$ \\
\hline 4 & 0 & $3.3^{\mathrm{ef}}$ & $5.7^{\mathrm{c}}$ \\
\hline 5 & 0 & $2.3^{\mathrm{fg}}$ & $3.5^{\mathrm{e}}$ \\
\hline 0 & 1 & $9.6^{\mathrm{a}}$ & $11.1^{\mathrm{a}}$ \\
\hline 0 & 2 & $8.0^{\mathrm{b}}$ & $8.5^{\mathrm{b}}$ \\
\hline 0 & 3 & $5.2^{\mathrm{d}}$ & $6.0^{\mathrm{c}}$ \\
\hline 0 & 4 & $3.8^{\mathrm{e}}$ & $4.6^{\mathrm{d}}$ \\
\hline 0 & 5 & $1.3^{\mathrm{g}}$ & $3.1^{\mathrm{e}}$ \\
\hline \multicolumn{2}{|c|}{ Mean } & 5.26 & 7.04 \\
\hline \multicolumn{2}{|c|}{ F-test } & $* *$ & $* *$ \\
\hline \multicolumn{2}{|c|}{ LSD@5\% } & 1.04 & 0.88 \\
\hline \multicolumn{2}{|c|}{$\mathrm{CV} \%$} & 11.74 & 7.39 \\
\hline
\end{tabular}

** Significant @ $\mathrm{P}<0.01$, Means with same letter within a column are not significantly different at $p<0.05$ ANOVA at least significance difference (LSD), $\mathrm{CV}=$ percent of coefficient variation, IBA= Indol-3-Butyric acid and NAA $=\alpha$-naphthalene Acetic Acid
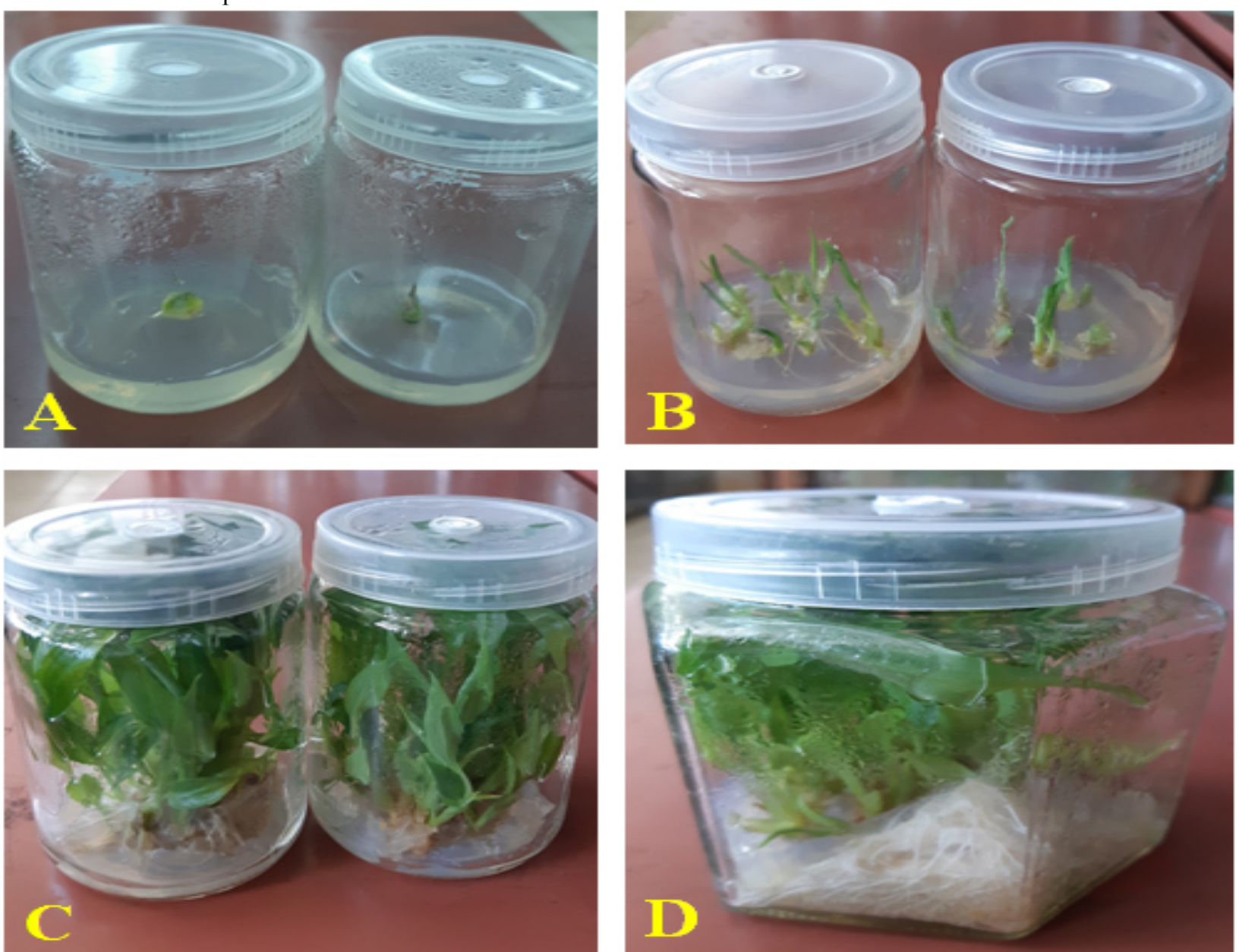

Figeur 1: In vitro protocol optimization for micro propagation of ginger cv. Volvo A) in vitro initiation of explants with suppemented MS media, $30 \mathrm{~g} / \mathrm{L}$ sucrose and $7 \mathrm{~g} / \mathrm{L}$ palnt propagated agar B) multiplied the clean plants to MS media, BA and KIN, 30g/L sucrose for six weeks C) subculted the micro shoot to MS media, $2 \mathrm{mg} / \mathrm{L} \mathrm{BA}$ and $0.5 \mathrm{mg} / \mathrm{L} \mathrm{KIN}, 30 \mathrm{~g} / \mathrm{L}$ sucrose for eight weeks and D) root induction per shootlets in $1 / 2 \mathrm{MS}$ media $30 \mathrm{~g} / \mathrm{L}$ sugar and $1 \mathrm{mg} / \mathrm{L}$ NAA in six weeks. 


\section{Acclimatization stage}

The rooted plantlets were remove carefully from the rooting medium and transplanted in plastic pots containing sterile mixture of forest soil, coffee husk and sand soil ( 2:1:1) ratio respectively and covered with plastic and transparent covers and gradually removing the covers after 2 weeks to hardening of plantlets. After six weeks, the plantlets were acclimatized and the survival percentage reached to $96 \%$ of plantlets (figure- 2). The acclimatization of micro propagated plants was important to help the plantlets to be converted from heterotrophic to autotrophic by promoting photosynthetic enzymes (Hazarika B.N., 2003). Following these steps the acclimatization of seedling was plant at pot and cement bug to produced edible rhizomes effectively and this practice is easy to do in home garden.
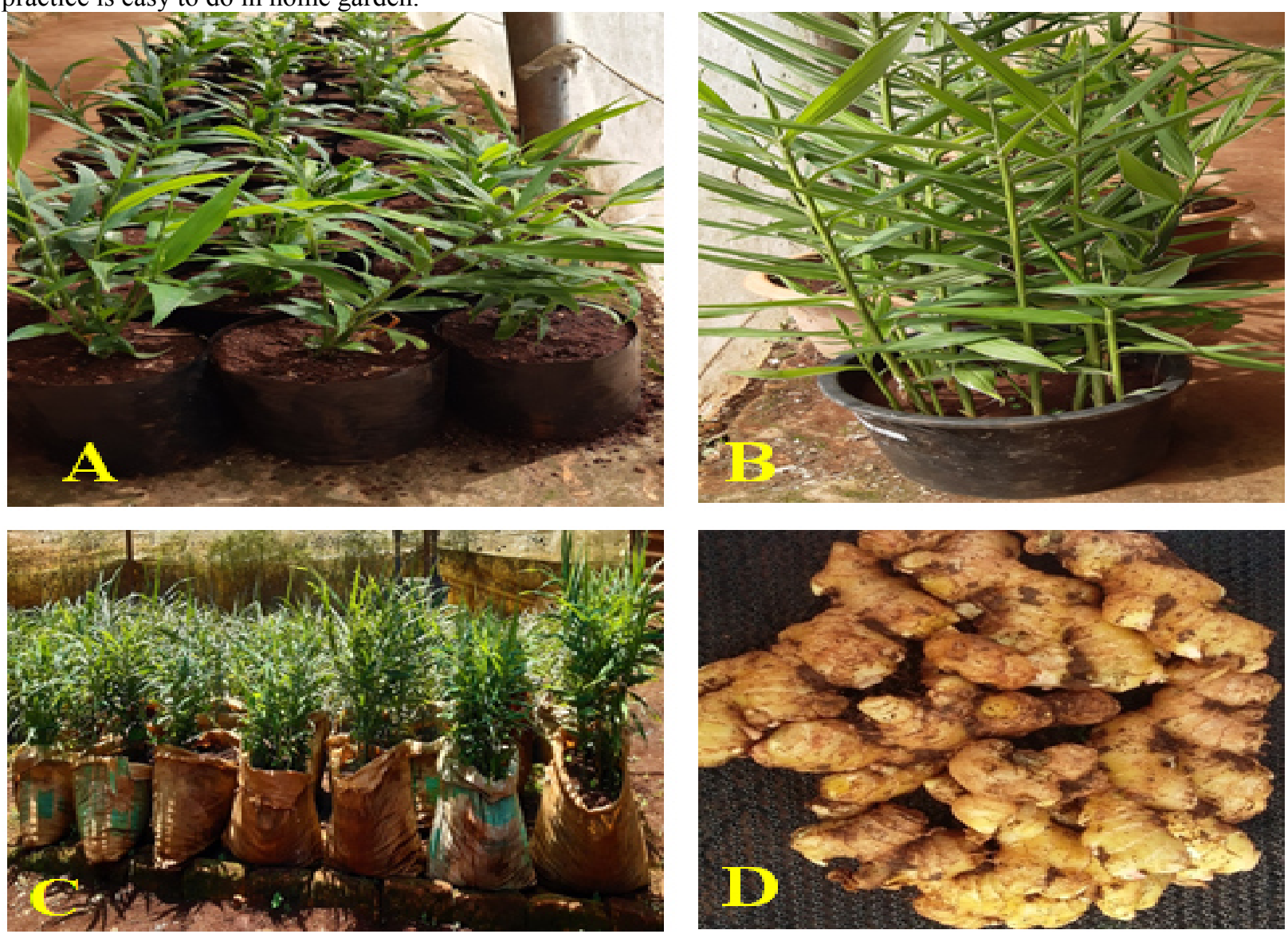

Figure 2: Acclimatization of ginger cv. Volvo in the greenhouse with forest soil, sand, and coffee husk at 2:1:1 ratio respectively A) in single polyethylene bug for nine weeks B) planted on pot for three months C) planted on cement bug for five month D) rhizomes setting in pot and cement bug after eight months

\section{CONCLUSION}

According to findings of present study, the micro propagation of ginger (Zingiber officinale Rosc.) cv. Volvo using rhizome sprout bud explants and plant growth regulators is very successful for in vitro mass propagation of this plant for commercial laboratory.

\section{Acknowledgements}

The author would like to acknowledge Ethiopia Institute of Agricultural Research (EIAR) for financial support and Jimma Biotechnology Research laboratory staff members for their advice and technical support of ginger cv. Volvo through in vitro culture. Highest gratitude is also extended to Areka Agricultural Research Center (AARC) for the collection and send Jimma Biotech laboratory of ginger cultivar.

\section{References}

Berihu Mengs 2018. Control of Contamination and Explants phenolics in Ginger accession (Zingiber officinale Rosc.) In Vitro Cultures., International Journal of Pharmaceutical Science and Research, 6(02):14-24.

Biruk A, Wondyifraw T, Kassahun B, (2012). In vitro propagation of Ethiopian ginger (Zingiber officinale Rosc.) cultivars: Evaluation of explant types and hormone combinations. African Journal of Biotechnology. 11(16):3911-3918. 
Gawel, N.J.; Robacker, C.D. and Corly, W.L.,(1990). In vitro propagation of Miscanthus sinensis. HortScience. 25(10): 1291-1203.

GenStat . 2012. GenStat Procedure Library Release PL 18.2. Edition 4. VSN International Ltd. Roth Amsted Experimental Station. UK.

Habetewold K, Bekele K, Kasahun S, Tariku H (2015). Prevalence of bacterial wilt of ginger (Z. Officinale Rosc.) caused by Ralstonia solansearum (Smith) in Ethiopia. International Journal of Research Studies in Agricultural Sciences. 1 (6): 14-22.

Hartmann, H.T.; Kester, D.E.; Davis, F.T. and Geneve, R.L.,(1997). Plant Propagation: Principles and Practices. $6^{\text {th }}$ Ed., Prentice-Hall, New Jersey.

Hazarika, B.N. Acclimatization of tissue cultured plants. Curr. Sci., 2003; 85: 1705-1712.

Nayak, S. and Naik, P.K. (2006). Factors Effecting In Vitro Microrhizome Formation and Growth in Curcuma longa L. and Improved Field Performance of Micropropagated Plants, Science Asia. 32: pp.31-37.

Newman M., (2001). Nomenclatural notes on Zingiberaceae. J. Bot. Vol. 58(1): 173-174.

Purseglove JW (1972). Tropical crops: Monocotyledons, $1^{\text {st }}$ edition, Longman group Limited, UK, London, pp. 52-54.

Simmonds, N.W. 1986. Evolution of crop plants. Longman Sci. \& Tech. England, pp. 339.

Tariku H, Kassahun S, Gezahegne G (2016). First report of ginger (Zingiber officinale) bacterial wilt disease in Ethiopia. Res.J. Agriculture and Forestry Sci. 4(4): 5-9.

Zhao, D.W. 2002. High quality and production of ginger- theory and technology. China Agricultural Publishing Company, Beijing. pp10-30. 